\title{
Research on Multiple Linear Regression of Stock Investment Value based on the Empirical Analysis of the A-share Pharmaceutical Industry in Shanghai and Shenzhen Stock Markets
}

\author{
Hongwen Song, Li Han * \\ Qufu Normal University, Rizhao, Shandong, 276826, China \\ *hanli@qfnu.edu.cn
}

\begin{abstract}
This paper selects 30 listed companies in the A-share pharmaceutical industry in Shanghai and Shenzhen stock markets and 17 financial indicators. Through the extraction of common factors of financial indicators, multiple linear regression models are used to determine the company's residual earnings per share and the company's various capabilities. The results show that the company's ability to develop has the greatest impact on the company's residual earnings per share. It also proves the importance of the company's fundamental analysis and provides a basis for small and medium investors to make real value investments.
\end{abstract}

Keywords: Stock Value; Factor Analysis; Multiple Linear Regression; Common Factors; Small and Medium Investors.

\section{Research Background}

At present, with the continuous improvement of China's stock market trading policies and China's increasing strict requirements on the information disclosure status of listed companies, the operating status of major listed companies can be effectively reflected in the company's public financial reports, and the company's operating status is determined. In order to determine the company's development prospects, the value of the stocks is ultimately determined, which in turn enables Chinese investors to greatly avoid the old random investment and blind obedience. The Chinese stock investment market continues to develop, and the scale of Chinese stockholders continues to grow.

However, although the stock value of listed companies can be predicted through the analysis of the company's financial data, there are also many stock price valuation models, but for most individual investors, it is neither realistic nor necessary to perform accurate analysis on a large amount of corporate data. On the one hand, many individual investors do not have financial knowledge, and it is difficult to reasonably analyze various financial data of the enterprise; on the other hand, the investment scale of individual investors is relatively small and generally does not spend a lot of time on corporate research. Therefore, this article aims to establish a simple stock value model to guide small and medium investors to invest in stocks, so as to further reduce blind obedience, reduce risks, and improve the effectiveness of the stock market.

\section{Theoretical Basis}

\subsection{Selection of Dependent Variables}

Stock market investment returns can be divided into two parts, normal income and residual income. The normal return is the basic return of the investment amount. It is the minimum return rate required by investors for investment. To compensate for the risk-free interest rate and inflation rate of the funds, one-year Treasury bond interest rates can be used (to simplify the model, it is assumed that investors only One-year investment) is approximated instead, the normal return can be expressed by multiplying the interest rate of the treasury bond by the total investment of the shareholders, that is, the net assets of the enterprise. Residual income is the "excess" income that an enterprise brings to investors through normal operations and the effectiveness of capital. It is the value that the enterprise 
really creates. Obviously, when investors make investments, they bear certain risks, not only for the preservation of capital, but also for the pursuit of residual income.

Residual income can be the net profit created by the enterprise minus the normal income. At the same time, in order to avoid the influence of the number of shares of different companies, the residual income per share can be used to express the pursuit of investors. Then the formula for the residual earnings per share in year $t$ is:

$$
P R I_{t}=\frac{N P_{t}}{S_{t}}-\frac{r_{t} * N A_{t}}{S_{t}}
$$

Among them, $P R I_{t}$ represents the residual earnings per share in year $\mathrm{t}, \quad N P_{t}$ represents the net profit in year $\mathrm{t}, \quad S_{t}$ represents the number of stocks in year $\mathrm{t}, \quad r_{t}$ represents the interest rate of one-year treasury bonds in year $\mathrm{t}, N A_{t}$ represents the net assets in year $\mathrm{t}$.

\subsection{Choice of Explanatory Variables}

Through the fundamental analysis of listed companies, it is possible to effectively obtain the operating and future development status of listed companies, and various financial indicators, including corporate solvency, operating capacity, profitability, and development capacity, better reflect the company's The past operating conditions and future development prospects. It is undeniable that the factors that affect the investment value of a company involve a wide range of factors, such as the management ability of managers, the goals of the company, the sense of social responsibility of the company, etc., as well as the personal behavior of shareholders may also affect the company's development. However, given that the above indicators are difficult to quantify, random Volatility is large, and real data is not easy to obtain, so for small and medium investors, the reference significance is far less than the various financial indicators of the enterprise. Therefore, this article only analyzes the financial indicators of listed companies to get the company's investment value.

\section{Empirical Research}

\subsection{Selection of Samples}

Table 1. Selected listed company

\begin{tabular}{|c|c|c|c|c|c|}
\hline $\begin{array}{c}\text { Stock } \\
\text { code }\end{array}$ & Company Name & $\begin{array}{c}\text { Stock } \\
\text { code }\end{array}$ & Company Name & $\begin{array}{c}\text { Stock } \\
\text { code }\end{array}$ & Company Name \\
\hline 002817 & Huangshan Capsule & 300878 & $\begin{array}{c}\text { Weikang } \\
\text { Pharmaceutical }\end{array}$ & 300636 & $\begin{array}{c}\text { Tonghe } \\
\text { Pharmaceutical }\end{array}$ \\
\hline 300841 & Kanghua Biology & 300573 & Xing Qi Eye Drops & 000403 & Palin Biology \\
\hline 002370 & $\begin{array}{c}\text { Asia-Pacific } \\
\text { Pharmaceutical }\end{array}$ & 688658 & $\begin{array}{c}\text { Yuekang } \\
\text { Pharmaceutical }\end{array}$ & 603520 & Stellite \\
\hline 603087 & Ganli Pharmaceutical & 300452 & Shanhe Yasuke & 000739 & $\begin{array}{c}\text { Puluo } \\
\text { Pharmaceutical }\end{array}$ \\
\hline 002773 & $\begin{array}{c}\text { Kanghong } \\
\text { Pharmaceutical }\end{array}$ & 603998 & $\begin{array}{c}\text { Fangsheng } \\
\text { Pharmaceutical }\end{array}$ & 600211 & $\begin{array}{c}\text { Tibet } \\
\text { Pharmaceutical }\end{array}$ \\
\hline 688298 & Orient Biosciences & 605116 & Oritech & 603811 & $\begin{array}{c}\text { Sincere } \\
\text { Pharmaceutical }\end{array}$ \\
\hline 688317 & Zhijiang Biology & 002019 & Yifan Pharmaceutical & 600851 & Haixin shares \\
\hline 300584 & Haichen Pharmaceutical & 002737 & $\begin{array}{c}\text { Sunflower } \\
\text { Pharmaceutical }\end{array}$ & 300142 & Watson Bio \\
\hline 300086 & Kangzhi Pharmaceutical & 600566 & Jichuan Pharmaceutical & 688526 & Keqian Biology \\
\hline 688117 & Sino Bio & 300143 & Yingkang Life & 600521 & $\begin{array}{c}\text { Huahai } \\
\text { Pharmaceutical }\end{array}$ \\
\hline
\end{tabular}


This article simply renumbers the listed companies in the A-share pharmaceutical industry in Shanghai and Shenzhen stock markets, uses MATLAB to generate random numbers, selects 30 manufacturing companies (see Table 1), and collects the major financial statements of these 30 manufacturing companies in 2020 And various financial indicator data.

\subsection{Selection of Indicators}

In the selection of financial indicators, this article refers to some indicators adopted in existing studies at home and abroad. Based on the accessibility of data information, 17 financial indicators are selected as the initial indicators for model construction, and the indicators reflect the aspects of the enterprise. Different, divided into 4 groups, namely the solvency, operating ability, profitability and development ability of the enterprise. See Table 2 for specific indicators and groupings.

Table 2. Selected financial indicators

\begin{tabular}{|c|c|c|}
\hline Grouping & Financial Indicators & Variable \\
\hline \multirow{3}{*}{ Solvency } & Current ratio & $X_{1}$ \\
\hline & Quick ratio & $X_{2}$ \\
\hline & Asset-liability ratio & $X_{3}$ \\
\hline \multirow{5}{*}{ Operating capacity } & Accounts receivable turnover rate & $X_{4}$ \\
\hline & Inventory turnover rate & $X_{5}$ \\
\hline & Liquid assets turnover rate & $X_{6}$ \\
\hline & Fixed asset turnover rate $X_{-}$7 & $X_{7}$ \\
\hline & Total asset turnover rate & $X_{8}$ \\
\hline \multirow{4}{*}{ Profitability } & Operating profit margin & $X_{9}$ \\
\hline & Net profit margin & $X_{10}$ \\
\hline & Gross profit margin & $X_{11}$ \\
\hline & Return on total assets & $X_{12}$ \\
\hline \multirow{5}{*}{ Development ability } & Operating income growth rate & $X_{13}$ \\
\hline & Growth rate of total assets & $X_{14}$ \\
\hline & Operating profit growth rate & $X_{15}$ \\
\hline & Net profit growth rate & $X_{16}$ \\
\hline & Net assets growth rate & $X_{17}$ \\
\hline
\end{tabular}

\subsection{Data Preprocessing}

Part 1: Positive processing of indicators

The positive index is also called the benefit index. The larger the positive index data, the better the benefit, while the negative index is the opposite. In the above indicators, except for the asset-liability ratio, the larger the better, and the asset-liability ratio represents the liabilities borne by each unit of assets, so it is a negative indicator. For the convenience of statistical analysis, the reciprocal of the asset-liability ratio is taken as the analysis indicator, that is, the asset-liability ratio is positively processed. After processing, all indicators become positive indicators.

Part 2: Standardization of indicators

Since the units and magnitudes of the above indicators are not the same, if the original indicator data is directly used for analysis, it will cause indicators with higher values to play a greater role in the model, and correspondingly weaken the role of indicators with low values. 
By standardizing the index data, the values are all in the $(0,1)$ interval, eliminating the influence of the value size, making the indicators comparable, and avoiding numerical problems caused by larger data.

Part 3: Factor Analysis

First of all, in the selected financial indicators of each listed company, due to the financial relevance, the financial indicators are not completely linearly independent. When the model is processed, the correlation between the explanatory variables will cause the model to appear multicollinearity. Greatly affect the accuracy of the model. Therefore, before establishing a model, it is necessary to deal with the correlation of various indicators.

Secondly, various financial indicators can reflect the company's operating conditions. Then, these financial indicators must have certain common factors, which cannot be observed or described in reality, but they play a vital role in corporate analysis.

Factor analysis can not only solve the multicollinearity problem of each explanatory variable, but also can extract the common recessive factors in the index, which is convenient for in-depth analysis of the factors that really work in each index, while effectively reducing the number of independent variables and strengthening the regression strength.

\begin{tabular}{|c|c|c|}
\hline \multicolumn{3}{|c|}{ KMO and Bartlett's Test } \\
\hline \multicolumn{2}{|c|}{ Kaiser-Meyer-Olkin Measure of Sampling Adequacy. } & .681 \\
\hline \multirow{3}{*}{$\begin{array}{l}\text { Bartlett's Test of } \\
\text { Sphericity }\end{array}$} & Approx. Chi-Square & 948.960 \\
\hline & df & 136 \\
\hline & Sig. & .000 \\
\hline
\end{tabular}

Figure 1. KMO and Bartlett's Test

KMO tests whether the partial correlation between variables is strong enough, and Bartlett's sphericity test is used to judge whether the correlation matrix is an identity matrix. From the Bartlett test in Figure 1, it can be seen that the significance is 0.000 , and the hypothesis that each variable is independent is rejected, that is, there is a strong correlation between the variables. At the same time, the KMO test is 0.681 , indicating that the degree of overlap of information between the variables is acceptable, and factor analysis will yield better results.

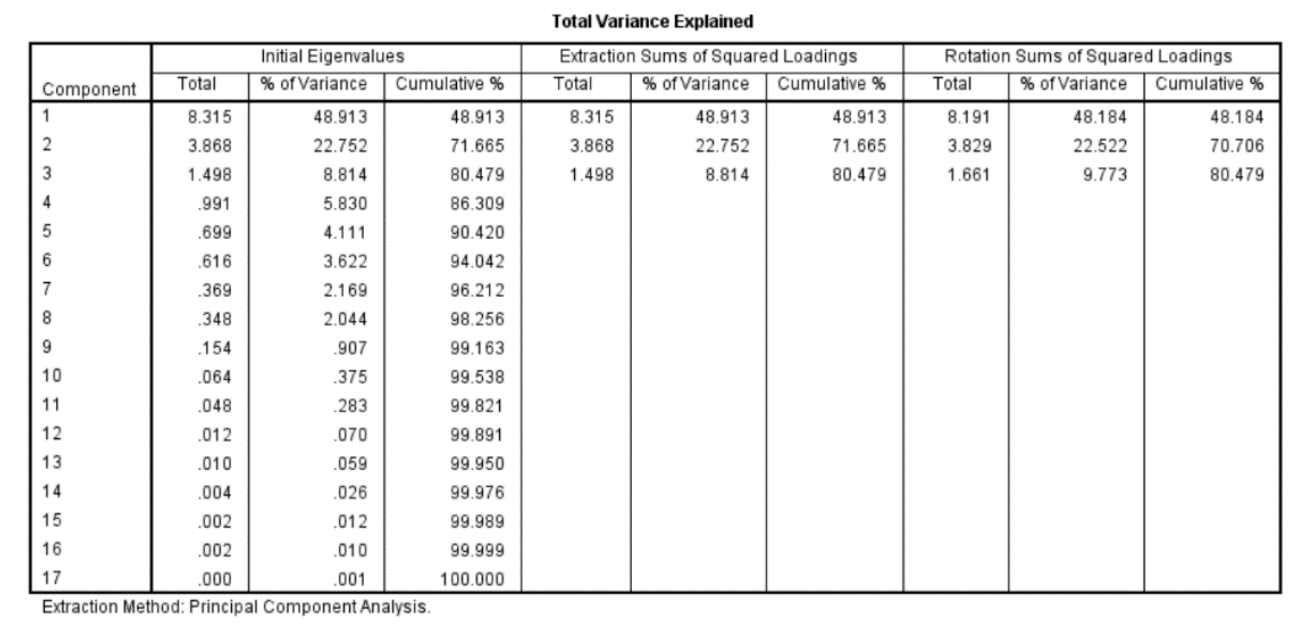

Figure 2. Total Variance Explained

It can be seen from Figure 2 that the eigenvalue of the first principal component is 8.315 , which means that it carries 8.315 original variables. The variance of the first principal component accounts for $48.913 \%$ of the variance of all principal components, and the variance of the first three principal 
components the contribution rate reached $80.479 \%$, so the use of the first three principal components is sufficient to describe the above 17 financial indicators.

Factor analysis requires the extracted factors to have actual meanings. In order to make the coefficients in the factor loading matrix more significant, the initial factor loading matrix is now rotated to redistribute the relationship between the factors and the original variables, which makes it easier to explain.

As shown in Figure 3, each financial index is interpreted as the coefficient of each principal component in the direction of the column, and the calculation formula for each factor is given. Reading by line reflects the load of each factor in each variable, that is, the degree of influence of each factor on each variable.

\begin{tabular}{|l|r|r|r|}
\hline \multicolumn{4}{|c|}{ Rotated Component Matrix } \\
\hline & \multicolumn{3}{|c|}{ Component } \\
\hline & 1 & \multicolumn{1}{c|}{2} & \multicolumn{1}{l|}{3} \\
\hline Zscore $(\mathrm{X} 1)$ & .105 & .920 & .214 \\
Zscore $(\mathrm{X} 2)$ & .127 & .926 & .199 \\
Zscore $(\mathrm{X} 3)$ & .047 & .892 & .201 \\
Zscore $(\mathrm{X} 4)$ & .183 & -.462 & .103 \\
Zscore $(\mathrm{X} 5)$ & .134 & -.015 & -.832 \\
Zscore $(\mathrm{X} 6)$ & .344 & -.631 & .366 \\
Zscore $(\mathrm{X} 7)$ & .936 & -.020 & .068 \\
Zscore $(\mathrm{X} 8)$ & .816 & -.292 & .261 \\
Zscore $(\mathrm{X} 9)$ & .720 & .509 & -.003 \\
Zscore $(\mathrm{X} 10)$ & .732 & .512 & .019 \\
Zscore $(\mathrm{X} 11)$ & .269 & .288 & .772 \\
Zscore $(\mathrm{X} 12)$ & .981 & .032 & .078 \\
Zscore $(\mathrm{X} 13)$ & .969 & -.079 & .014 \\
Zscore $(\mathrm{X} 14)$ & .907 & .029 & .086 \\
Zscore $(\mathrm{X} 15)$ & .968 & -.096 & -.042 \\
Zscore $(\mathrm{X} 16)$ & .958 & -.089 & -.057 \\
Zscore $(\mathrm{X} 17)$ & .863 & .052 & .110 \\
\hline
\end{tabular}

Figure 3. Rotated Component Matrix

The replacement of various financial indicators is as follows:

$$
\begin{gathered}
Z X_{1}=0.105 F_{1}+0.920 F_{2}+0.214 F_{3}+\varepsilon_{1} \\
\ldots \ldots \\
Z X_{17}=0.863 F_{1}+0.052 F_{2}+0.110 F_{3}+\varepsilon_{17}
\end{gathered}
$$

In the formula, $Z X_{1} \ldots Z X_{17}$ are standardized financial indicators, $F_{1}, \quad F_{2} . \quad F_{3}$ are selected three factors after rotation, $\quad \varepsilon_{1} \ldots \quad \varepsilon_{17}$ are other indicators that cannot be explained by three factors Influencing factors.

By analyzing the calculation formula of each factor, it can be seen that factor 1 mainly reflects the company's development ability, and also reflects the company's operating ability and profitability, factor 2 mainly reflects the company's solvency, and factor 3 mainly reflects the company's profitability.

\subsection{Model Establishment}

Based on the above processed indicators, SPSS was used to perform multiple linear regression on the data. 


\begin{tabular}{|l|c|c|c|c|}
\hline \multicolumn{1}{|c|}{ Model Summary } \\
\hline Model & R & R Square & $\begin{array}{c}\text { Adjusted R } \\
\text { Square }\end{array}$ & $\begin{array}{c}\text { Std. Error of } \\
\text { the Estimate }\end{array}$ \\
\hline 1 & $.949^{\text {a }}$ & .901 & .890 & .33214770 \\
\hline
\end{tabular}
a. Predictors: (Constant), REGR factor score 3 for analysis 1,
REGR factor score 2 for analysis 1, REGR factor score 1 for
analysis 1

Figure 4. Model Summary

As shown in Figure 4, the adjusted R-squared is 0.890 , indicating that the model has a good regression effect and strong interpretation.

\begin{tabular}{|c|c|c|c|c|c|c|}
\hline \multicolumn{7}{|c|}{ ANOVA $^{a}$} \\
\hline \multicolumn{2}{|c|}{ Model } & $\begin{array}{l}\text { Sum of } \\
\text { Squares }\end{array}$ & df & Mean Square & $\mathrm{F}$ & Sig. \\
\hline \multirow[t]{3}{*}{1} & Regression & 26.132 & 3 & 8.711 & 78.956 & $.000^{\mathrm{b}}$ \\
\hline & Residual & 2.868 & 26 & .110 & & \\
\hline & Total & 29.000 & 29 & & & \\
\hline \multicolumn{7}{|c|}{ a. Dependent Variable: Zscore(V) } \\
\hline \multicolumn{7}{|c|}{$\begin{array}{l}\text { b. Predictors: (Constant), REGR factor score } 3 \text { for analysis 1, REGR factor score } 2 \text { for } \\
\text { analysis 1, REGR factor score } 1 \text { for analysis } 1\end{array}$} \\
\hline
\end{tabular}

Figure 5. ANOVA

In Figure 5, the F test is performed on the model. The significance of the $\mathrm{F}$ test is 0.000 . The model as a whole passes the F test, and the error probability of the model is less than one in a thousand.

Coefficients $^{\mathrm{a}}$

\begin{tabular}{|c|c|c|c|c|c|c|}
\hline \multirow[b]{2}{*}{ Mode } & & \multicolumn{2}{|c|}{ Unstandardized Coefficients } & \multirow{2}{*}{$\begin{array}{c}\begin{array}{c}\text { Standardized } \\
\text { Coefficients }\end{array} \\
\text { Beta }\end{array}$} & \multirow[b]{2}{*}{$t$} & \multirow[b]{2}{*}{ Sig. } \\
\hline & & $\mathrm{B}$ & Std. Error & & & \\
\hline \multirow[t]{4}{*}{1} & (Constant) & $-8.211 \mathrm{E}-17$ & .061 & & .000 & 1.000 \\
\hline & $\begin{array}{l}\text { REGR factor score } 1 \text { for } \\
\text { analysis } 1\end{array}$ & .938 & .062 & .938 & 15.208 & .000 \\
\hline & $\begin{array}{l}\text { REGR factor score } 2 \text { for } \\
\text { analysis } 1\end{array}$ & .077 & .062 & .077 & 1.254 & .221 \\
\hline & $\begin{array}{l}\text { REGR factor score } 3 \text { for } \\
\text { analysis } 1\end{array}$ & .124 & .062 & .124 & 2.003 & .056 \\
\hline
\end{tabular}

Figure 6. Coefficients

From Figure 6, the results of multiple linear regression can be obtained:

$$
V=0.938 F_{1}+0.077 F_{2}+0.124 F_{3}+\varepsilon
$$

Among them, $\mathrm{V}$ is the stock value of the enterprise, and $\varepsilon$ is the random error term.

The $\mathrm{t}$ test was performed on the three factors, and it was found that the $\mathrm{P}$ value of the $F_{1}$ factor $\mathrm{t}$ test was 0.000 , which passed the $\mathrm{t}$ test at a significance level of $1 \%$, and the $F_{2}$ factor failed the model $\mathrm{t}$ test. The significance of $\quad F_{3}$ was 0.056 . Pass the t-test at a significance level of $10 \%$.

It can be seen from this that the company's future development capabilities have the greatest impact on the company's stock value, and the company's operating capacity and profitability also have a greater impact on the stock value. In comparison, the company's solvency has an impact on the company's stock value. The intensity is relatively weak. 


\section{Conclusion}

Through the establishment of a simple stock value model, it can be seen that the financial index data of each company plays an important role in the evaluation of the company, and provides some suggestions for small and medium-sized enterprises in China: When conducting investment activities, not only should pay attention to technical analysis, but also strengthen the company's Fundamental analysis of the company, only with the fundamental analysis of the company as a guide, it is more likely to obtain greater returns in the stock market.

When paying attention to the company's various financial data, we must pay attention to the company's development capabilities, and choose companies with good development prospects to invest as much as possible to reduce capital risks.

Multiple linear regression has a good effect on the stock value of pharmaceutical companies, and provides some important references for simple stock analysis and forecasting for small and medium investors in our country, and increases the possibility of more non-professionals entering the investment industry.

\section{References}

[1] Guo Qixing. Research on the valuation of A-share pharmaceutical industry based on Ohlson model[D]. Yunnan University of Finance and Economics, 2016.

[2] Cheng Haibo. Research on the logit model of stock investment value--An empirical analysis of the Shanghai A-share manufacturing industry [A]. China Accounting Association. Proceedings of the 2009 Academic Annual Conference of the Financial Management Professional Committee of China Accounting Association [C]. China Accounting Association: China Accounting Association, 2009: 8.

[3] He Ping, Lan Wei, Ding Yue. Can my country's stock market be predicted? --Based on the perspective of the combined LASSO-logistic method [J]. Statistical Research, 2021, 38(05): 82-96. 